\title{
The parameters effect on the structural performance of damaged steel box beam using Taguchi method
}

\author{
Boshra A. El-taly ${ }^{1}$ Mohamed F. Abd El Hameed ${ }^{2}$
}

Received: 20 August 2017 / Accepted: 12 January 2018 / Published online: 24 January 2018

(c) The Author(s) 2018. This article is an open access publication

\begin{abstract}
In the current study, the influence of notch or opening parameters and the positions of the applied load on the structural performance of steel box beams up to failure was investigated using Finite Element analysis program, ANSYS. The Taguchibased design of experiments technique was used to plan the current study. The plan included 12 box steel beams; three intact beams, and nine damaged beams (with opening) in the beams web. The numerical studies were conducted under varying the spacing between the two concentrated point loads (location of applied loads), the notch (opening) position, and the ratio between depth and width of the notch with a constant notch area. According to Taguchi analysis, factor $X$ (location of the applied loads) was found the highest contributing parameters for the variation of the ultimate load, vertical deformation, shear stresses, and the compressive normal stresses.
\end{abstract}

Keywords Box steel beam $\cdot$ Structural performance $\cdot$ Finite element analysis $\cdot$ Opening parameters $\cdot$ Taguchi method

\section{Introduction}

Design errors, corrosion, lack of proper maintenance, substandard materials, fatigue damage and vehicle-caused accidental damage are considered as the major problems in the steel structures (Kim and Yoon 2010). Fatigue damage induces cracks in the tension flange of the girders and it is critical to the service life of the girders (May et al. 2016; Zhu 2016; Fisher and Roy 2015). Corrosion reduces steel sections that can cause deterioration in steel structures. Various researches investigated the influence of the corrosion and fatigue damage on the behavior of steel structures and they also presented different methods to retrofit these steel elements. In these researches, the structural steel element may be naturally deteriorated or artificially damaged. Gillespie et al. (1996) studied two full-scale I-girders. The two girders were removed from an old and deteriorated bridge and they have $9754 \mathrm{~mm}$ long, $610 \mathrm{~mm}$ deep. The flange has $229 \mathrm{~mm}$ wide. A uniform corrosion occurred along the length of

Boshra A. El-taly

boushra_eltaly@yahoo.com

1 Civil Engineering Department, Faculty of Engineering, Minoufia University, Shebeen El-kom, Egypt

2 Department of Mechanical Engineering, Faculty of Engineering, Minoufia University, Shebeen El-kom, Egypt the specimen. The corrosion concentrated within the bottom flange and the webs of the beams were not corroded. $40 \%$ reduction of the lower flange created these deteriorations. This corrosion caused a $29 \%$ reduction in the beam stiffness. Liu et al. (2001) carried out on wide steel beams with $2438 \mathrm{~mm}$ span three-point bending tests. In their studied, the tension flanges of specimens were completely cut. Their results indicated that this damage causes decreasing the maximum load of the intact beam from 200 to $106 \mathrm{kN}$. Shaat (2007) and Eltaly (2016) completely cut the bottom flanges of wide beams and box beams, respectively, at midspan to simulate a severe section loss in the steel beams. Shaat (2007) concluded that the flexural strength and stiffness of the girders was reduced by 60 and $54 \%$, respectively. Eltaly (2016) indicated that the strength of notched beam was dropped by $34 \%$. Tavakkolizadeh and Saadatmanesh (2001) estimated the effect of partial cutting of the tension flange using different depths of the cut (shallow and deep). These cutting simulated 80 and $40 \%$ losses in the area of the flange for the deep and shallow cutting depth, respectively. The difference between deep and shallow cuts was the ductility loss in the case of deep cut. Tavakkolizadeh and Saadatmanesh (2003) tested composite girders with the partial cutting of the tension flange to simulate 25,50 , and $100 \%$ loss of its tensile capacity. Kim and Brunell (2011) conducted an experimental program to estimate the effect 
of the notch level in the beam web at mid-span of the steel beams. Shulley et al. (1994) studied the effect of web damage of I-girders. Specimens were tested in three-point bending. The specimens were with $711 \mathrm{~mm}$ span. A hole with $100 \mathrm{~mm}$ diameter was manfactured within the shear span at mid-height of the web.

Section losses occurred also due to creating an opening in the steel beam webs for the passage of the horizontal utility ducts. Web openings could weaken the beam at the position of the opening and decrease its overall stiffness and load carrying capacity depending on the opening size, location and shape. The beams with rectangular web openings have the smaller ultimate loads than their equivalent beams with square or circular openings (Morkhade and Gupta 2015; Rodrigues et al. 2014; Chung et al. 2001). Li et al. (2015) tested continuous composite steel beams with and without openings in the web under two point loads. All the tested beams have the same details except the slab thickness and the reinforcement. Their results indicated that the stiffness and ultimate load decrease when creating openings in the steel web.

The literature revealed that a large number of investigations were done related to the artificially damaged beams and the beam with openings in steel web, these studies were done to characterize the behavior of the beams, and these studies are still being conducted. However, there are still gaps in understanding the behavior of these beams. One reason is that the beam performance may be different depending on the parameters of the notch (opening) and the load position; therefore, any conclusions are only valid for specific cases studied. Another reason is that much research has been conducted using one-factor-at-a-time approach. The amount of fluctuations in the study results reveals that the variables involved in the artificially damaged beams are dynamic in nature and beam responses are significantly related with the simultaneous variation of parameters during studies. Therefore, DOE technique has been used to make the analysis reliable and to investigate the effects of the notch parameters and the position of the load on different criteria simultaneously.

In the current research, twelve box steel beams were studied using FE analysis program, ANSYS to investigate their structural performance up to failure in terms of the maximum load and its corresponding deflection, the shear and normal stresses and the strain. Three steel box beam without opening (notch) were used and they were called control beams. These beams are valid in the position of the applied loads. In the current study, three factors at three levels were chosen as control factors. Normally, the full-factorial design would require $3 \times 3=27$ runs. The run cost and effort for such design could be unrealistic and prohibitive. The Taguchi-based DOE technique was investigated to plan the present study. Nine box steel beams with notches (opening) in the beam web were selected from 27 notched beams using Taguchi-based design technique were analyzed. Only few authors have used the Taguchi-based DOE technique in the domain of civil and/or structural engineering (Ghazy 2012; Ghazy and Abd El Hameed 2015; Kamble et al. 2016). To the best of the authors' knowledge of this work, there is no published work evaluating the artificially damaged beams or the steel beams with web openings and the effect of beam parameters on the single-performance characteristics in these beams using Taguchi-based DOE technique. Hence, it is a good idea to perform a comprehensive investigation using Taguchi-based DOE technique to analyze the effect of the damaged beam parameters for desired performance characteristics. Thus, the results can be used by the engineers who are willing to search for a suitable analysis of a damaged beam or beam with opening. Finally, necessary confirmation tests were numerically conducted to validate the results.

\section{Experimental design details}

The experimental design using Taguchi's method provides a simple, efficient, and systematic approach for the optimization of experimental designs for performance quality (Ross 1996). The traditional experimental design methods are too complex and difficult to use. Additionally, large numbers of runs have to be carried out when the number of parameters increases. Taguchi designed certain standard orthogonal arrays by which the simultaneous and independent evaluation of two or more parameters for their ability to affect the variability of particular process characteristics can be done in a minimum number of tests.

The beam parameters (control factors) chosen for the runs were: (1) ratio between width and depth of the notch $(H / B)$, (2) The distance between the applied loads $(X)$, and (3) The notch position (NP). Each parameter has three levels. The area of the notch (opening) was kept constant to be $3872 \mathrm{~mm}^{2}$. Table 1 indicates the factors and their levels. In this study, an L9 orthogonal array with three columns and nine rows was used as illustrated in Table 2. Use of a full factorial design $(3 \times 3 \times 3)$ reduced a total 27 sets of runs down to 9 runs, thereby decreasing cost, time, and effort. In addition, three control beams; CB1, CB2 and CB3 were

Table 1 Beam parameters and their levels used in the experiments

\begin{tabular}{llll}
\hline Parameter & Level (1) & Level (2) & Level (3) \\
\hline$H / B$ & 0.15 & 0.35 & 0.55 \\
$X(\mathrm{~mm})$ & 300 & 600 & 900 \\
$\mathrm{NP}$ & $\mathrm{A}$ & $\mathrm{B}$ & $\mathrm{C}$ \\
\hline
\end{tabular}


Table 2 Experimental plan using L9 OA-based Taguchi method

\begin{tabular}{llll}
\hline Beam code. & $H / B$ & $X$ & NP \\
\hline B1 & 0.15 & 300 & A \\
B2 & 0.15 & 600 & B \\
B3 & 0.15 & 900 & C \\
B4 & 0.35 & 300 & B \\
B5 & 0.35 & 600 & C \\
B6 & 0.35 & 900 & A \\
B7 & 0.55 & 300 & C \\
B8 & 0.55 & 600 & A \\
B9 & 0.55 & 900 & B \\
\hline
\end{tabular}

studied. The three beams are intact beams and the position of the applied loads (X) is varied; 300, 600 and $900 \mathrm{~mm}$.

All the studied steel beams have $1000 \mathrm{~mm}$ length, $50 \times 50 \mathrm{~mm}$ box cross section and $3 \mathrm{~mm}$ thickness as shown in Fig. 1. The material properties of the used beams are listed in Table 3. Notch positions are indicated in Fig. 2.

\section{FE modeling}

The FE analysis program, ANSYS was used to determine the structural performances up to the failure of the specimens. Solid185 elements were selected to simulate the studied beams (refer to Eltaly 2016; ANSYS 2009; Narmashiri and Jumaat 2011). Each element is defined by 8 nodes. There are three degrees of freedom (translations in $x, y$, and $z$ directions) at each node. Solid185 element has swelling, plasticity, creep, large strain, large deflection and stress stiffening capabilities. In the current model, geometric and material nonlinearities were both considered into account. Multi-linear Kinematic Hardening Constants approach was selected to simulate the material nonlinearity. This approach was selected for materials that obey von Mises yield criteria. The stress-strain curve of the steel material was defined. ANSYS program depends on Newton-Raphson method for updating the model stiffness. Load-control technique was selected in the current model. In this technique, the total load is applied. During the analysis, the load is divided into small load increments using the automatic time stepping option. This option was selected to decrease load step size when the convergence occurs for the given load step. The size of load step in the case of linear range should not be defined small and it was gradually decreased as the behavior of the beam changes from linear to non-linear stage. The load increases gradually until the beam failure occurs.

Volume was used to define the studied beam in the 3D-FE model of the studied beams. Then the material and the type of element were selected as explained above. After that, the beam model was meshed with mapped meshing technique that helps in controlling the number of elements. The analysis started with a $20 \mathrm{~mm}$ mesh size of the elements (coarse mesh) then the model was resolved with smaller and smaller meshes (mesh refinement). In this process, mesh sizes were considered as 10, 4 and $2 \mathrm{~mm}$. Their results were compared and from this comparsion process, it can be indicated that 2 and $4 \mathrm{~mm}$ mesh sizes give acceptable results and the difference in their results is small so that the mesh size was taken as $4 \mathrm{~mm}$. The FE simulation of the damaged beam is showed in Fig. 3.

\section{Results and discussion}

The performance of studied steel beams as obtained from the numerical model; peak load, normal stresses and strain (tensile and compressive), shear stresses and the maximum vertical displacement at the ultimate loads according to

Fig. 1 Intact beam details

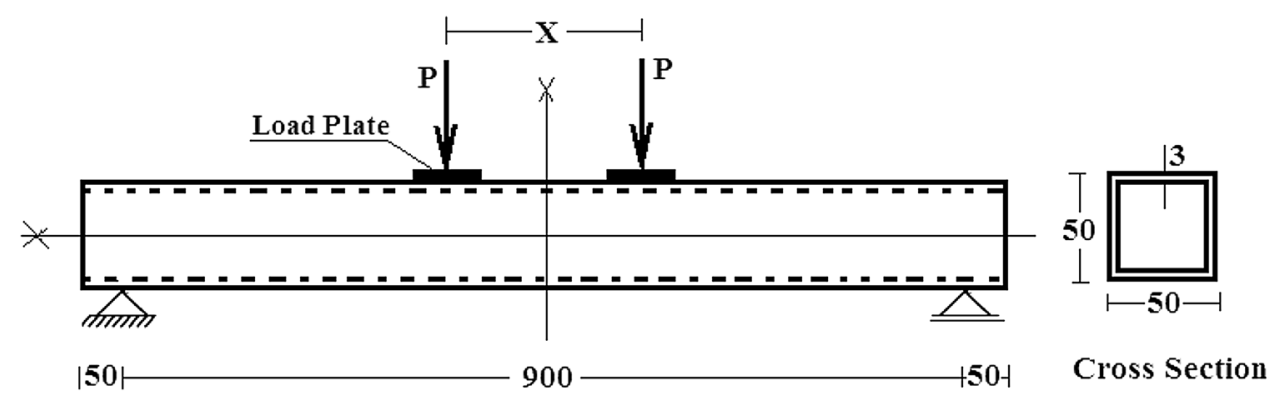

Table 3 Material properties of the used steel

\begin{tabular}{|c|c|c|c|c|c|c|}
\hline & \multirow[t]{2}{*}{ Modulus of elasticity (Gpa) } & \multirow[t]{2}{*}{ Density $\left(\mathrm{g} / \mathrm{cm}^{3}\right)$} & \multicolumn{2}{|c|}{$\begin{array}{l}\text { Tensile strength } \\
\text { (Mpa) }\end{array}$} & \multicolumn{2}{|l|}{ Strain } \\
\hline & & & Ultimate & Yield & Ultimate & Yield \\
\hline Steel & 200 & 7.8 & 370 & 250 & 0.0135 & 0.00125 \\
\hline
\end{tabular}


Fig. 2 Notch position (NP)

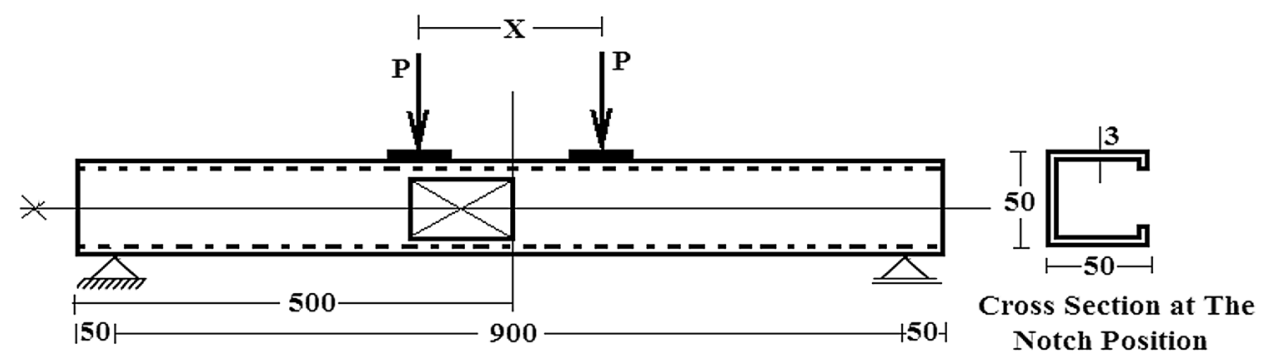

(a) Damaged beam at position $\mathrm{A}$

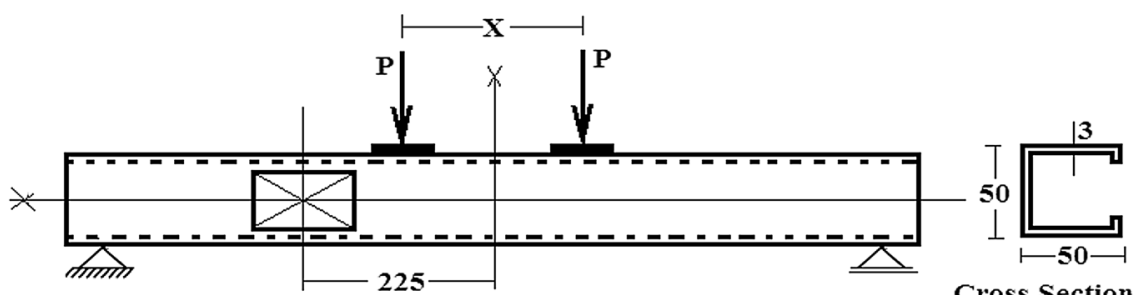

$$
150
$$

900

(b)Damaged beam at position B

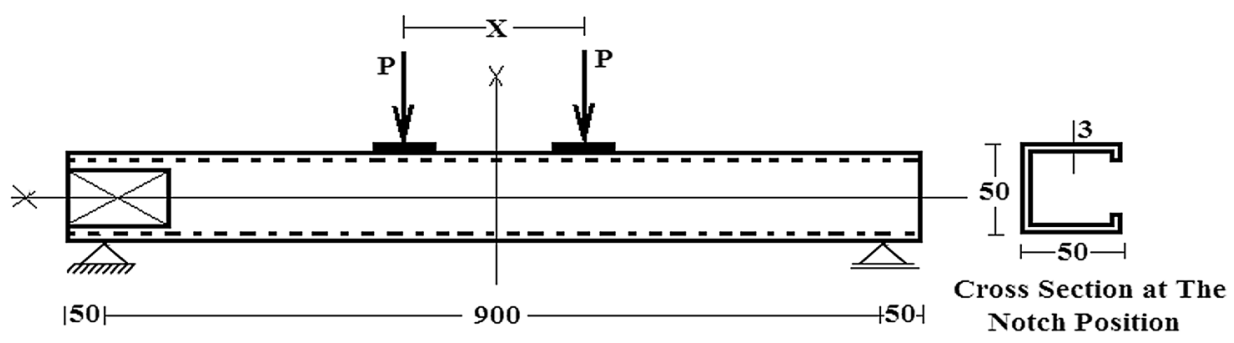

(c) Damaged beam at position $\mathrm{C}$

Fig. 3 Numerical model

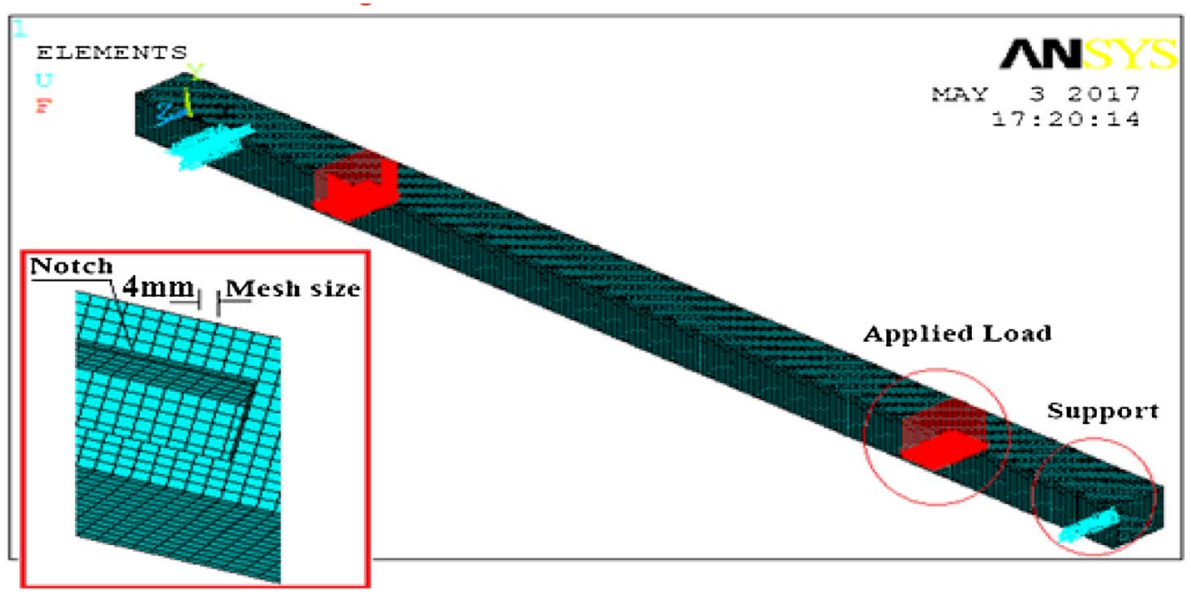

the proposed plan in different parameters are showed in Table 4. The results of the three intact beams; CB1, CB2 and CB3 in terms of the deformed shape, strain distribution, normal and shear stress distributions at the maximum loads are presented in Figs. 4, 5 and 6. This table and these figures indicated that $\mathrm{CB} 1$ and $\mathrm{CB} 2$ fail due to bending and on the other hand the failure occurs on CB3 due to shear. The normal stresses reach the ultimate tensile strength of the steel material; $370 \mathrm{Mpa}$ in CB1 and CB2. In CB3 beams, the applied load causes $360 \mathrm{Mpa}$ maximum normal 
Table 4 Numerical results of responses (raw data)

\begin{tabular}{|c|c|c|c|c|c|c|c|}
\hline \multirow[t]{2}{*}{ Beam no. } & \multirow[t]{2}{*}{$\operatorname{Pmax}(k N)$} & \multirow[t]{2}{*}{$\begin{array}{l}\text { Vertical defor- } \\
\text { mation (mm) }\end{array}$} & \multicolumn{2}{|c|}{$\begin{array}{l}\text { Normal stresses } \\
\text { (Mpa) }\end{array}$} & \multirow[t]{2}{*}{$\begin{array}{l}\text { Shear stresses } \\
(\mathrm{MPa})\end{array}$} & \multicolumn{2}{|l|}{ Strain } \\
\hline & & & Com. & Ten. & & Ten. & Com. \\
\hline CB1 & 21.92 & 31.779 & 370 & 370 & 140 & 0.01897 & 0.0223 \\
\hline $\mathrm{CB} 2$ & 37.38 & 27.37 & 370 & 370 & 180 & 0.013 & 0.042 \\
\hline CB3 & 77.82 & 2.91 & 350 & 360 & 188 & 0.033 & 0.08 \\
\hline B1 & 17.93 & 20.2 & 370 & 250 & 137 & 0.0130 & 0.0037 \\
\hline B2 & 30.87 & 8.311 & 370 & 299 & 173.3 & 0.0049 & 0.0182 \\
\hline B3 & 50.4 & 15 & 360 & 350 & 200 & 0.0018 & 0.0018 \\
\hline B4 & 18.37 & 20.65 & 370 & 370 & 193.6 & 0.013 & 0.03 \\
\hline B5 & 33.46 & 19.5 & 370 & 360 & 183 & 0.025 & 0.027 \\
\hline B6 & 77.82 & 2 & 350 & 350 & 197 & 0.02 & 0.02 \\
\hline B7 & 21.19 & 35.75 & 370 & 370 & 170 & 0.013 & 0.024 \\
\hline B8 & 25.26 & 17.2 & 360 & 360 & 134 & 0.0097 & 0.014 \\
\hline B9 & 77.82 & 2 & 340 & 350 & 193 & 0.002 & 0.002 \\
\hline
\end{tabular}
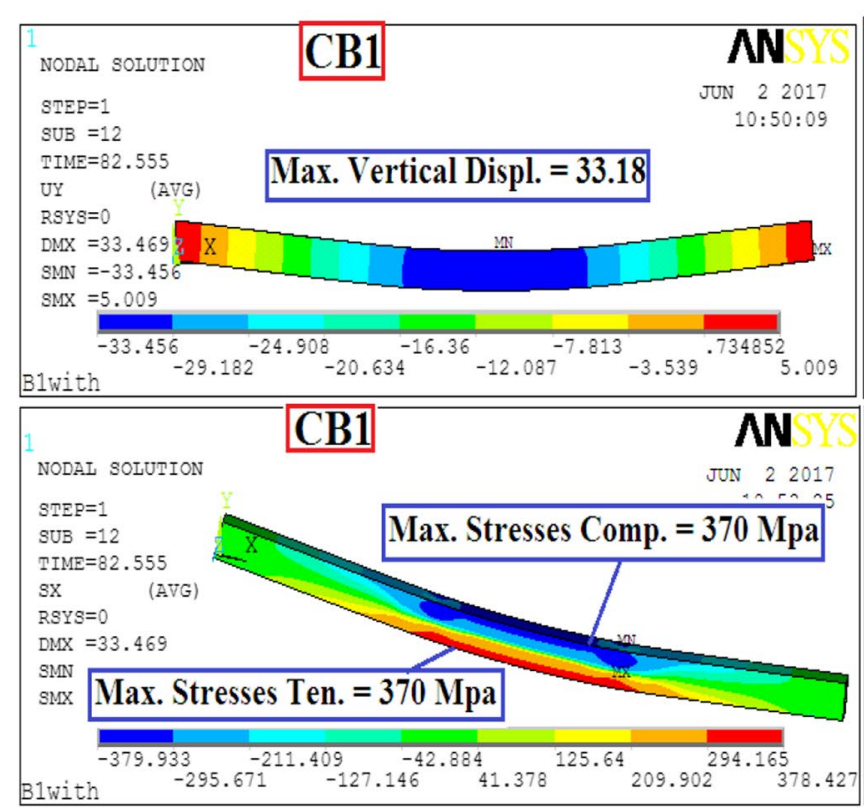

Fig. 4 Results of CB1 beam

stresses and 188 Mpa maximum shear stresses. In the three beams, the maximum stresses occur in the position of the applied loads and the surrounding area. Also this table and figures indicate that the beam deflection increases by decreasing the distance between the applied load while the maximum deflection in $\mathrm{CB} 1$ beams reaches at the midspan $31.70 \mathrm{~mm}$ at $21.92 \mathrm{kN}$ ultimate load and it reaches $27.37 \mathrm{~mm}$ at the mid-span at $37.38 \mathrm{kN}$ maximum applied load in CB2. On the other hand, there is no any notable deflection occurred at mid-span of CB3 and a local buckling appears on the top flange under the applied load. The maximums strain (tensile and compressive) is noticed at the position of the applied load.

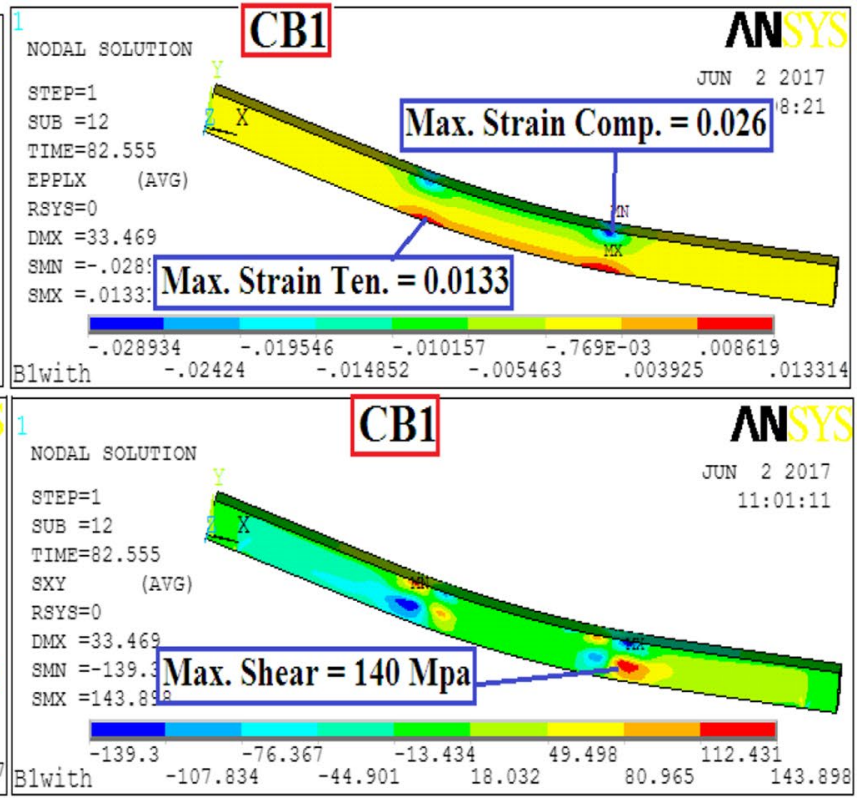

Shear and normal stresses, strain and vertical displacement distribution at the peak loads of the nine beams; B1 to B9 are indicated in Figs. 7, 8, 9, 10, 11, 12, 13, 14 and 15. It is clearly observed from Table 4 that B1 has the lowest peak load and B7 has the maximum lateral displacement. Also from this table and Figs. 7, 8, 9, 10, 11, 12, 13, 14 and 15 , it can be concluded that $\mathrm{B} 1, \mathrm{~B} 2, \mathrm{~B} 4, \mathrm{~B} 5$ and $\mathrm{B} 7$ reach the ultimate compressive strength of the steel. B4 and B7 reach the ultimate tensile strength of the steel (flexural failure) and on the other hand B3 reaches the steel shear strength (shear failure). Additionally, Figs. 7, 8, 9, 10, 11, 12, 13, 14 and 15 illustrate that in B1, B2, B3, B4, B5 and B8, the maximum stresses appear at the loads and the opening position and 

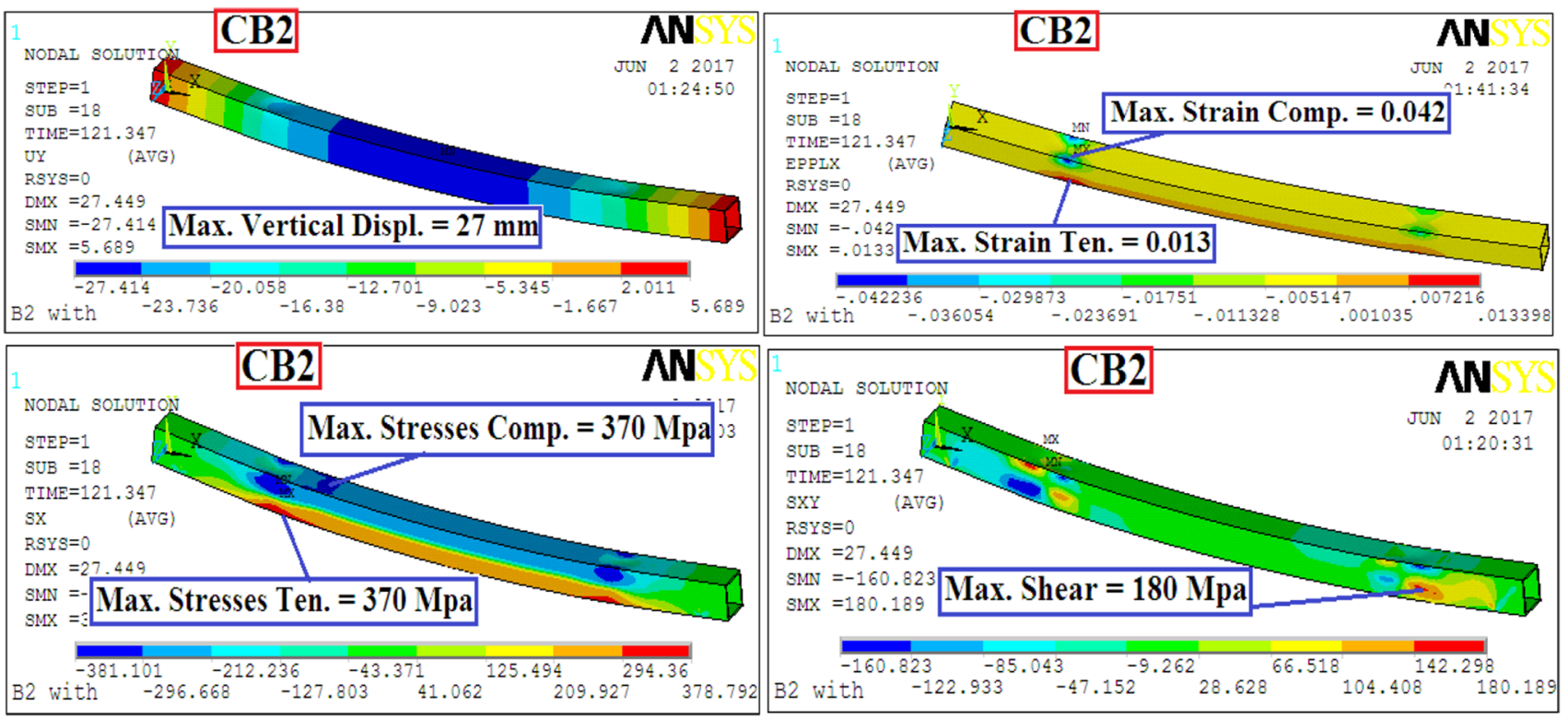

Fig. 5 Shear and normal stresses, strain and deflection distributions of CB2 beam
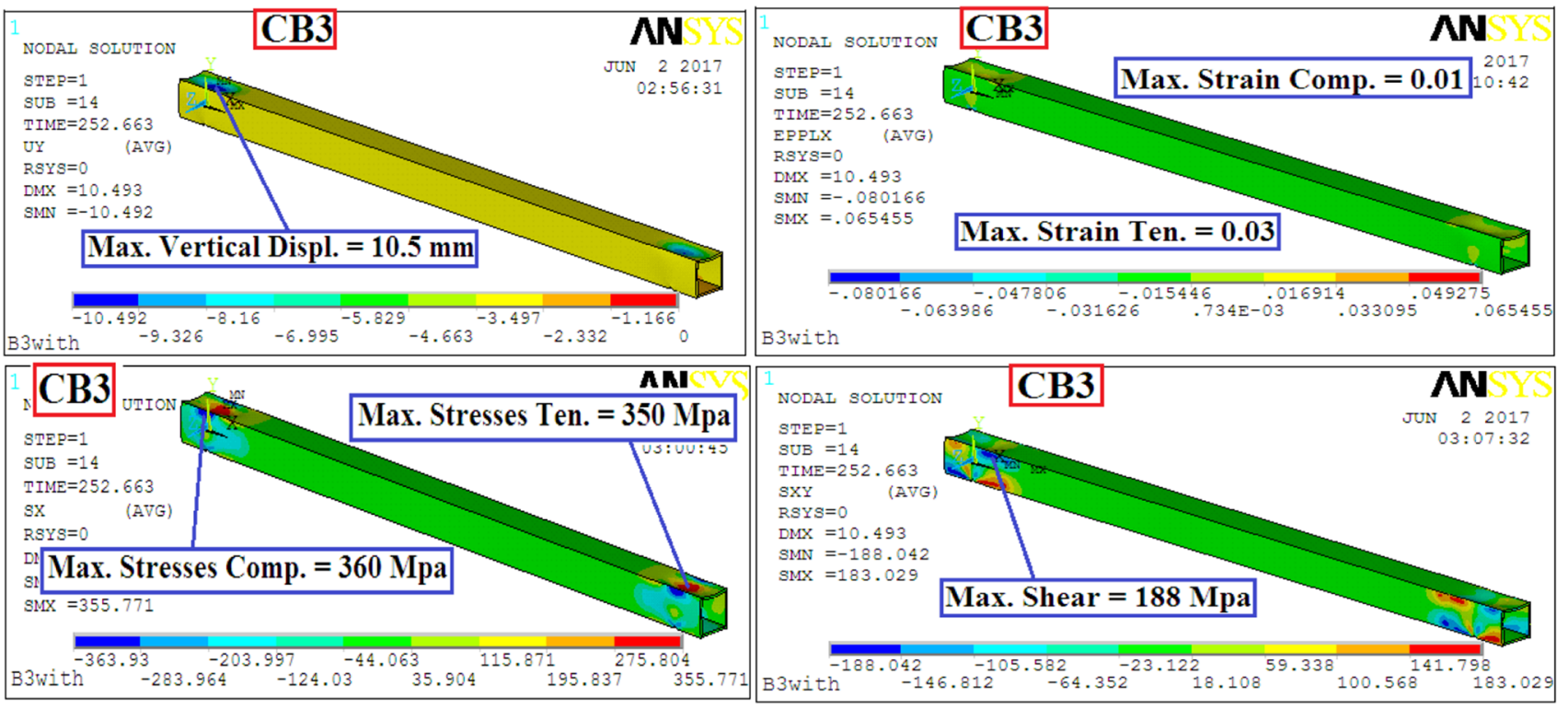

Fig. 6 Deflection, shear and normal stresses and strain distributions of CB3 beam

the surrounding area and on the opposite side the maximum stresses appear at the load position and the surrounding area.

The comparisons between the studied beams and the opposite control beams are depicted in Table 4 and Fig. 16. Comparing the results of B1, B4 and B7 beams with CB1 control beam indicates that the opening (notch) in the beam web near the mid-span and with the $H / B$ ratio $=0.15$ as in B1 does not have a notable effect on the beam stiffness and has effects on the beam ductility and strength. This notch decreases the ultimate load compared to the control beam with $18.20 \%$ and the corresponding deflection with $36.44 \%$ in respect to the CB1 control beam. Also the compression normal stress remains the maximum value as $370 \mathrm{Mpa}$ and on the other hand the peak tensile normal stress and shear stress decrease from 370 and $140 \mathrm{Mpa}$ in CB1 to be 250 and $137 \mathrm{Mpa}$ in B1 beam, respectively. Additionally, this comparison illustrates that the opening position B (B4) decreases the structural performance of the beam. The maximum load 


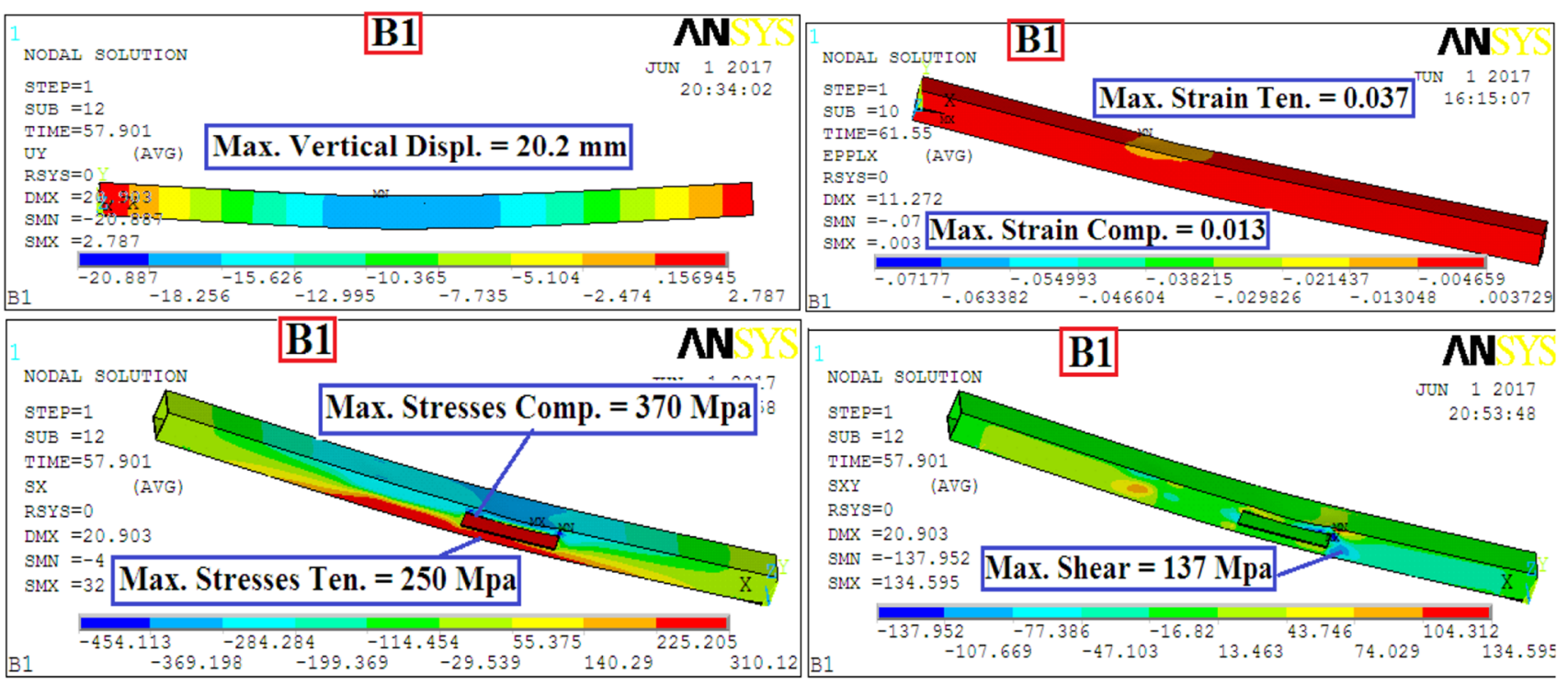

Fig. 7 Shear and normal stresses, strain and deflection distributions of B1
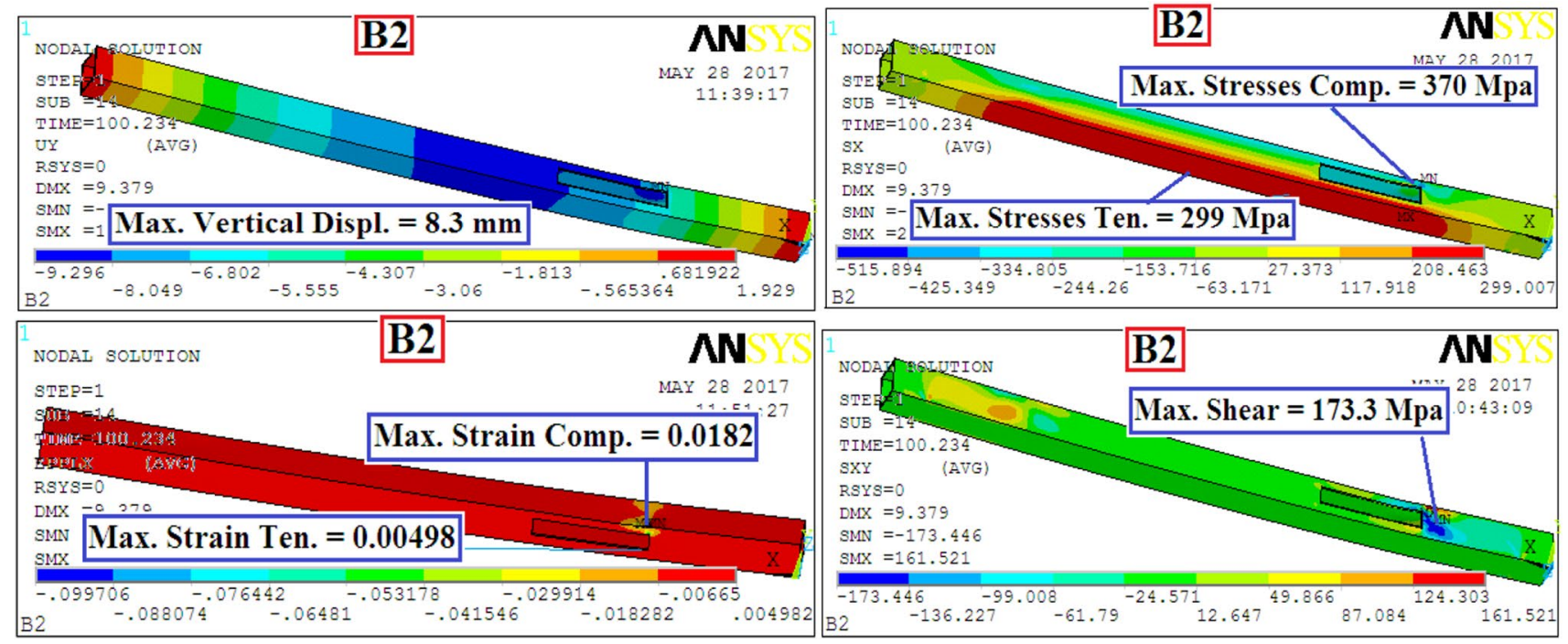

Fig. 8 Vertical deformation, shear and normal stresses, strain and distributions of B2 beam

dropped from $21.92 \mathrm{kN}$ in $\mathrm{CB} 1$ to $18.37 \mathrm{kN}$ in $\mathrm{B} 4$ with $16.2 \%$ reduction respect to $\mathrm{CB} 1$ and the maximum deflection in the beam reduces by about $35 \%$ compared with CB1. In addition, this compression shows that the occurrence the notch near the support and the load near the mid-span as in B7 beam does not give notable influence in ultimate load and normal stresses of the beam compared with $\mathrm{CB} 1$ but it has an effect on the strain and shear stresses. Hence, the shear stresses increases from $140 \mathrm{Mpa}$ in CB1 to be $177 \mathrm{Mpa}$ in B7. Creating the opening (notch) at the support increase the shear stresses in the beam and decrease the ability of the beam to carry the shear forces.
From Table 4 and Fig. 16, it can be clearly noticed that the ductility of the steel beam subjected to two applied loads with $600 \mathrm{~mm}$ separated distance between them (CB2) largely drops due to occurrence the web notch with $H / B=0.15$ and with $\mathrm{B}$ notch position; B2 beam. The deflection (at the mid-span) at the ultimate load decreases by about $69.63 \%$ compared with CB2. Also the strength of this beam reduces by $17.42 \%$ than $\mathrm{CB} 2$ and it stiffens does not appreciably change. This beam likes CB2 fails because it reaches the maximum compressive strength; $370 \mathrm{Mpa}$. The tensile normal stress and shear stresses reduce from 370 and $180 \mathrm{Mpa}$ in CB2 to be 299 and $173.3 \mathrm{Mpa}$ in 


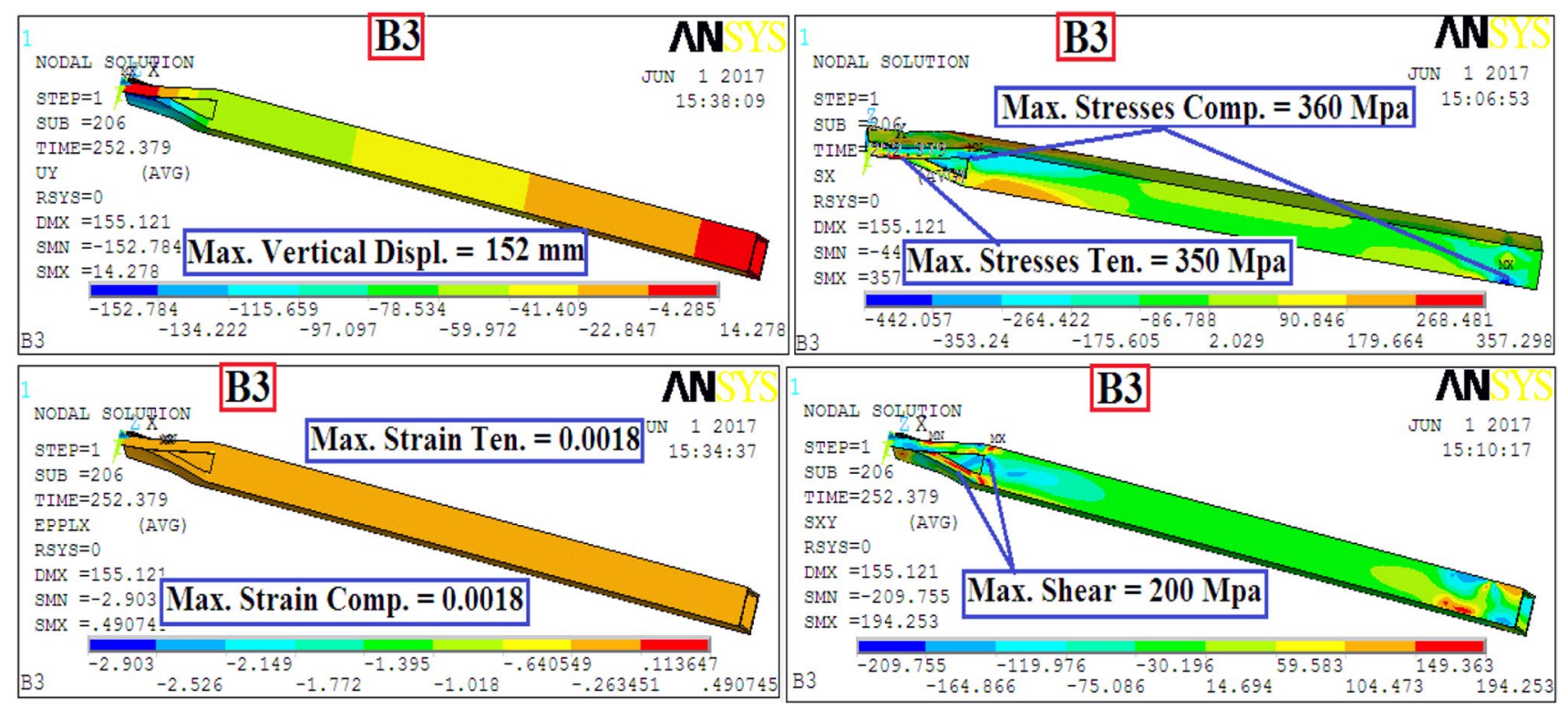

Fig. 9 Vertical deformation, shear and normal stresses, strain and distributions of B3
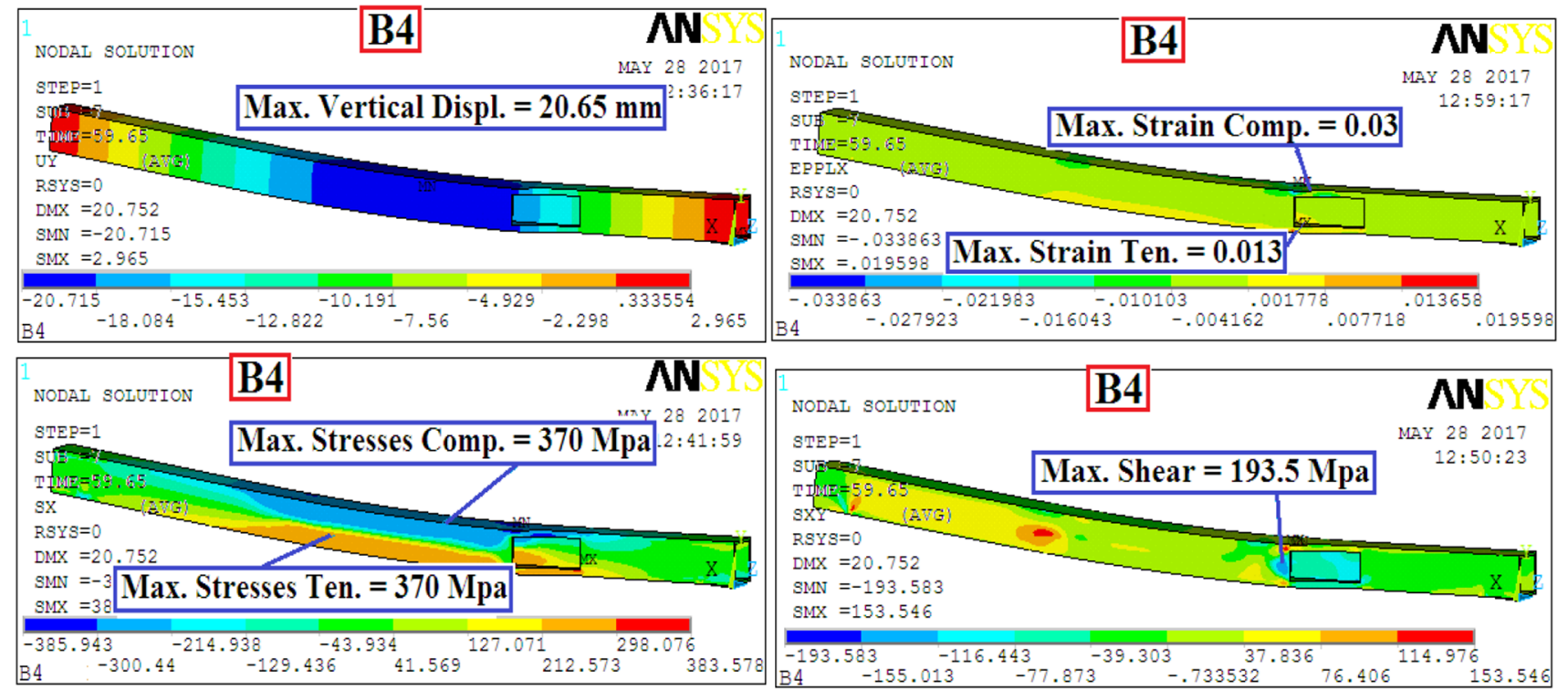

Fig. 10 Vertical deformation, strain, shear and normal stresses distributions of B4

B2 beam. This is because of the occurrence of the notch under the loads. The ultimate load and its corresponding deflection of B5 beam decline by about 10.48 and $28.75 \%$, respectively, than $\mathrm{CB} 2$ beam. B5 gives larger compressive and tensile strain than $\mathrm{CB} 1$ and it fails due to flexure as CB2. In addition, Table 4 and Fig. 16 shows that B8 (beam with $H / B=0.55$ ratio and $C$ position web opening) gives lower ultimate load by about $32.42 \%$ than CB2 beam. Its deflection at the ultimate load decreases by about $37.17 \%$ than $\mathrm{CB} 2$.
Table 4 illustrates that the structural behavior of CB3 beam in terms of the deflection, normal stresses and peak load does not affect by the occurrence of opening in the web at position B and A as in B6 and B9, respectively. It has an effect on the shear strength. These openings increase the actual shear stresses of the beam. In addition, this table shows that B3; this beam has web opening with $H / B=0.15$ and the opening at position $C$ collapses at $35.24 \%$ ultimate load lower than CB3 beam. Furthermore, this beam reaches the maximum shear stresses. This is because of the position 

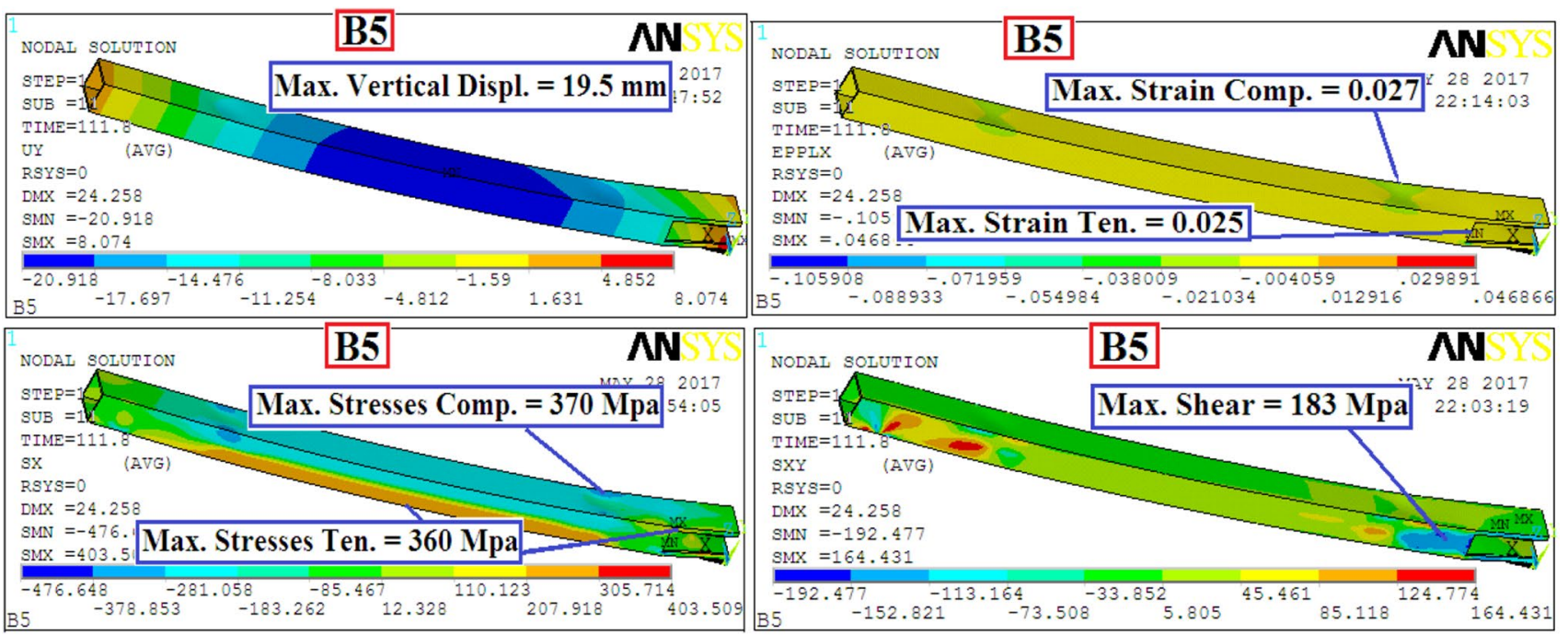

Fig. 11 Vertical deformation, strain, shear stresses and normal stresses distributions of B5
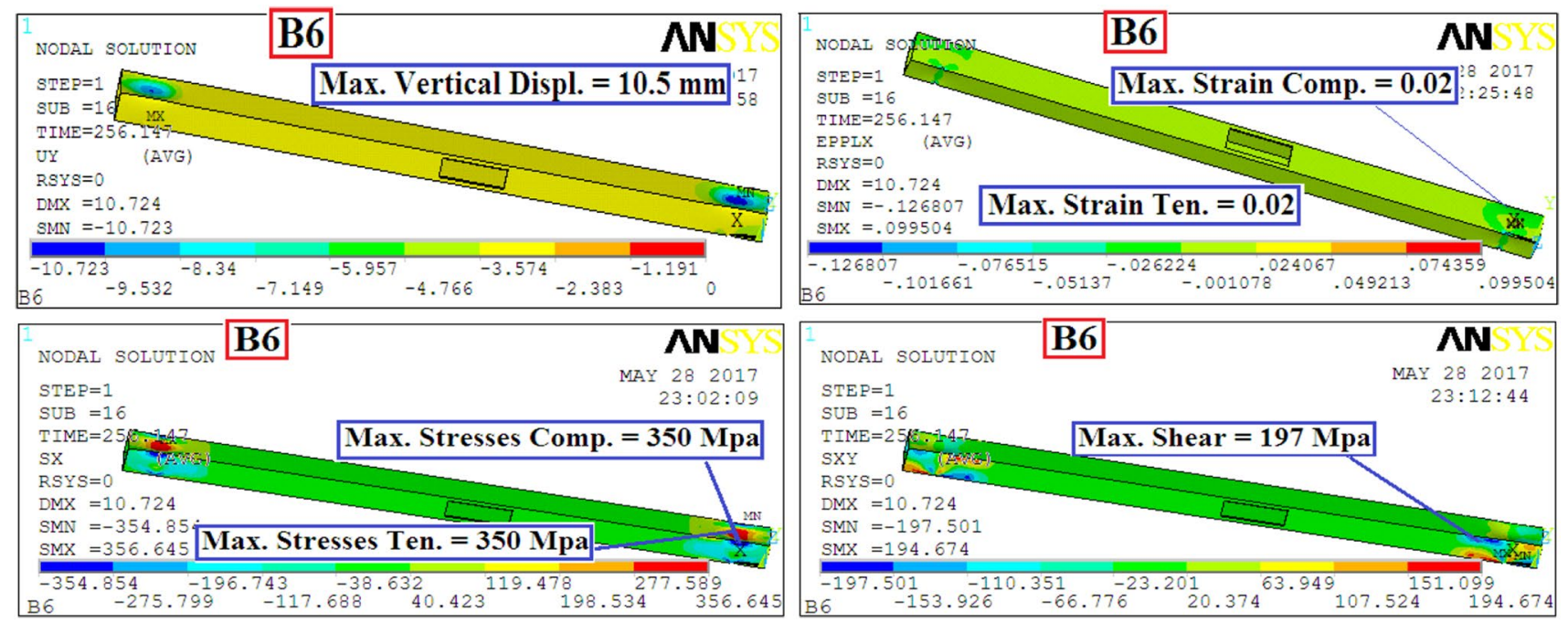

Fig. 12 Shear stresses and normal stresses, vertical deformation and strain distributions of B6 beam

of opening under the applied load and in the maximum shear zone of the beam.

Figure 16 Load-deflection curves at the mid-span of damaged beams and control beams.

In addition to the determination of desired (critical) beam parameters for each response, the response table from Taguchi method was used. In the case of the applied load, the desired beam has the lowest ultimate load. The beams have the maximum value for the other structural performances; normal stresses, shear stresses, strain and lateral displacement are the critical. Because Table 4 is orthogonal, it is possible to separate out the effect of each beam parameter on the response at different levels. The procedure is group the data by the factor level for each column in the orthogonal array and takes the mean of them. For example, the mean of the maximum load for the factor $(H / B)$ at 1,2 , and 3 Levels can be calculated by $1-3,4-6$, and 7-9 averaging runs, respectively.

The mean of any response for each level of the other process parameters can be calculated in a similar manner. The results for peak load were listed in Table 5. The difference between the maximum and the minimum value (delta) of the data for the peak load are listed in Table 5. The most effective controllable factor was the maximum of these values. On the other hand, the significance of the role that every controllable factor plays over the performance characteristic can be obtained by examining these values. The effect of each control factor can be determined from the value of 


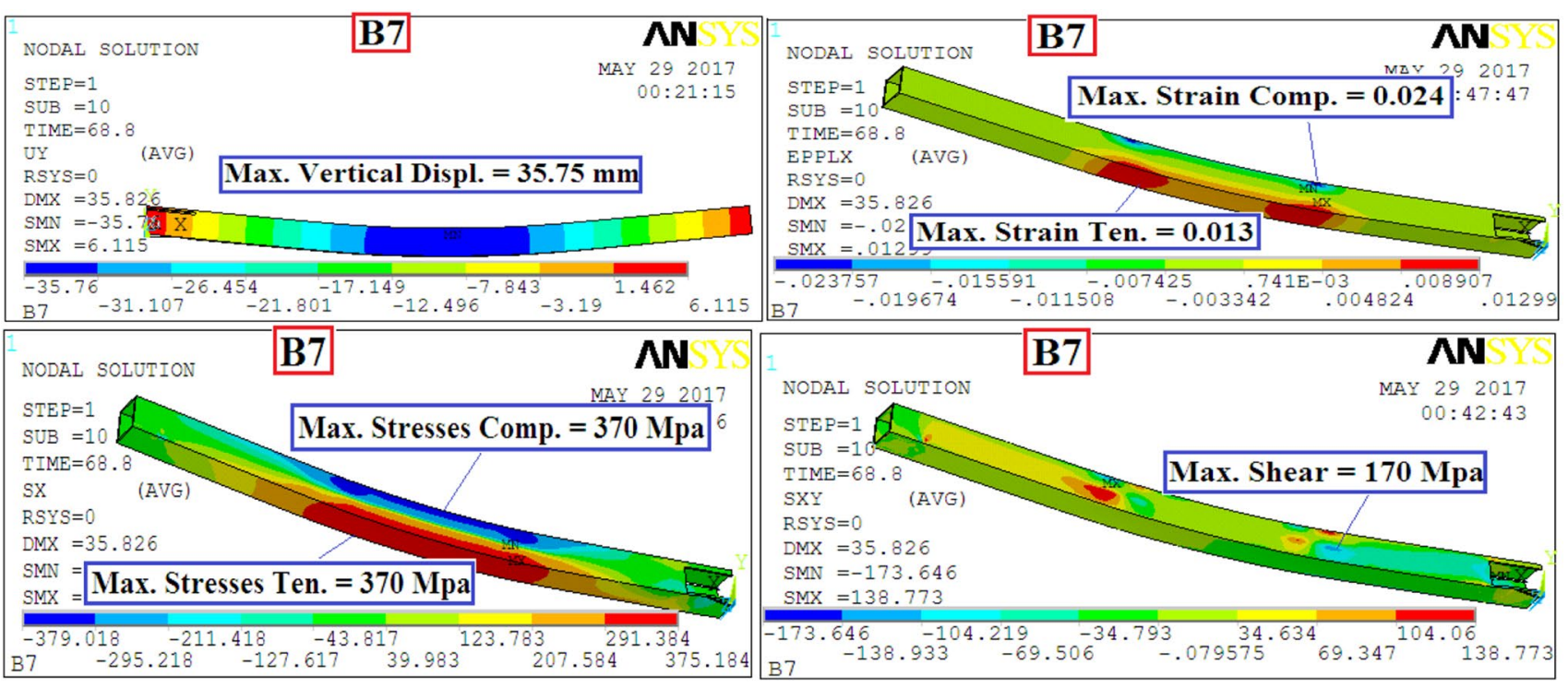

Fig. 13 Vertical deformation, strain, shear and normal stresses distributions of B7
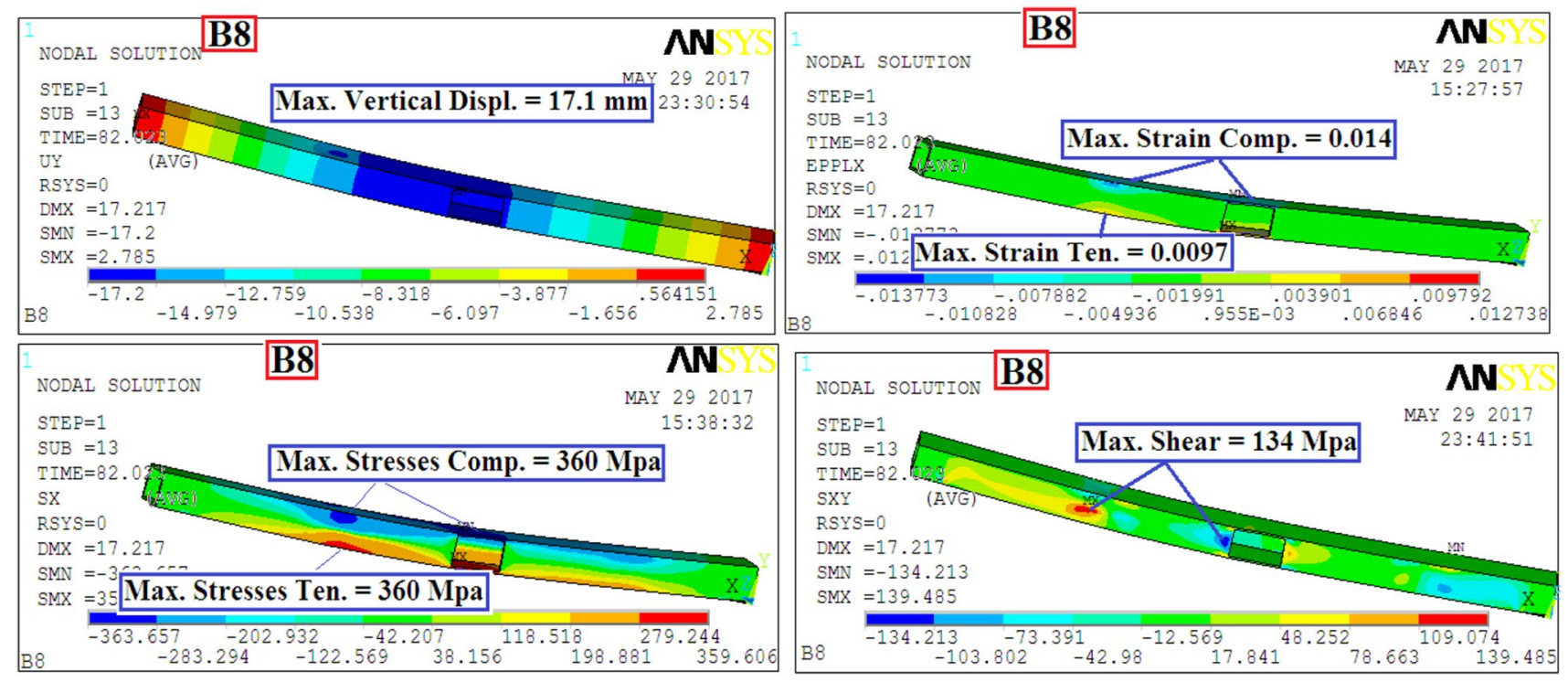

Fig. 14 Vertical deformation, strain, stresses shear and normal stresses distributions of B8

delta, based on which Table 5 shows, factor $X$ has the largest delta and thus has the most significant influence (Rank 1) on the peak load. From the analysis of Table 5, it was observed that the percentage contribution of the control factors affecting the peak load is $X(74.3 \%), H / B(15 \%)$, and NP $(10.7 \%)$.

Figure 17 shows the main effects plot of peak load. From this figure, it is observed that the variation of parameter $X$ has a critical role on peak load, which increases with parameter $X$. It is revealed from the same figure that the $H / B$ factor has the same trend of factor NP. The critical value of factor $(H / B)$ is at $0.35 \mathrm{~mm}$. From the same figure, it is obvious that factor NP has the weakest effect on peak load and its critical position of the notch is at $\mathrm{B}$.

From Table 5 and Fig. 17, the beam parameter levels for minimum peak load (critical beam) can be given as for $H / B=0.15, X=300 \mathrm{~mm}$, and NP at C. Because these combination parameters are selected from the response table (Table 5) according to Taguchi analysis, and these combination parameters are not found in the orthogonal array (Table 3), the confirmation test analysis for this beam is processed. It is a good idea to plan on running an additional sample at this condition. The expected result is considered to 

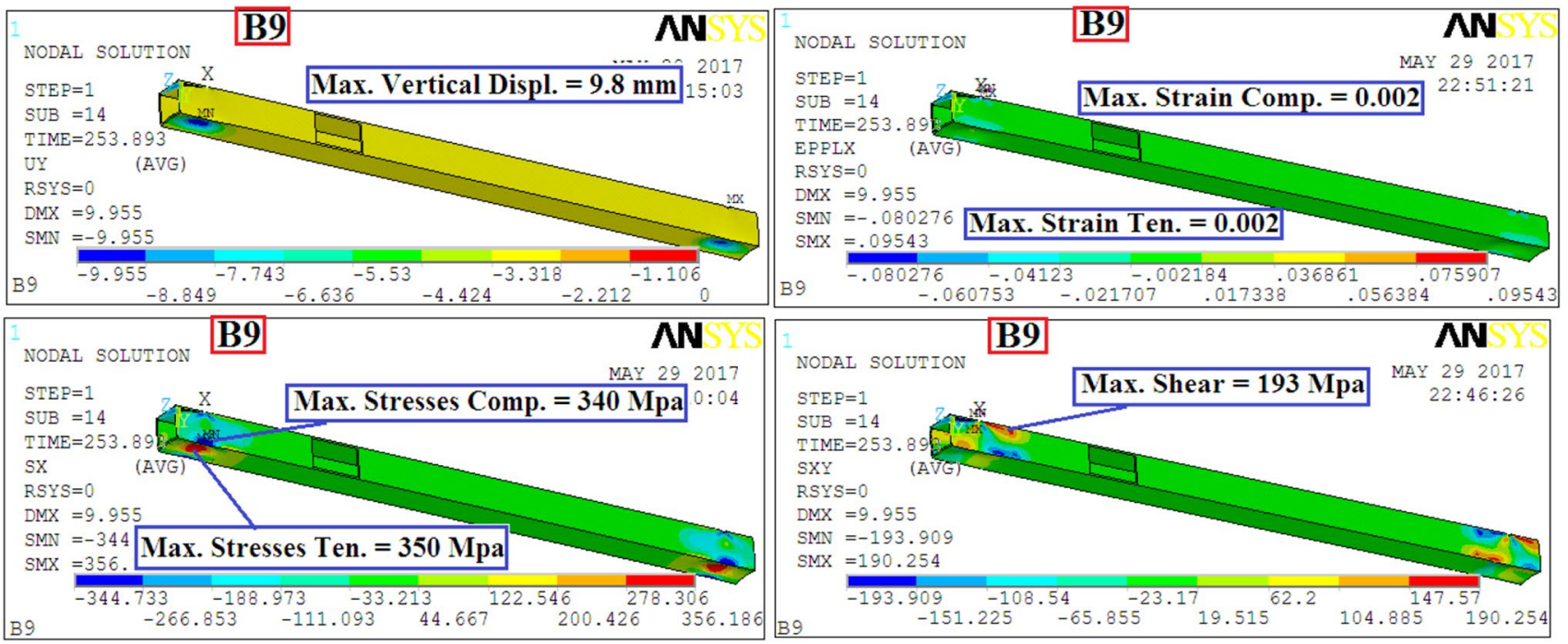

Fig. 15 Vertical deformation, strain, shear and normal stresses distributions of B9

be confirmed when the mean of a number of samples studied at the selected condition falls close to it.

The result of confirmation test analysis is compared with the initial condition of design operating parameters. It is obvious from Table 5, that Beam No 1 (B1) has the lowest peak load value $(17.93 \mathrm{kN})$ compared to the other beams. Therefore, it can be concluded that Beam No.1 possesses initial setting parameters. Table 5 shows the compared results of the desired beam parameters $(H / B=0.15, X=300 \mathrm{~mm}$, and $\mathrm{NP}$ at $\mathrm{C})$ and initial design parameters $(H / B=0.15$, $X=300 \mathrm{~mm}$, and NP at A). For the single performance characteristic, the peak load is reduced from 17.93 to $14.14 \mathrm{kN}$. The predicted (calculated) peak load using the optimal level of desired (critical) beam parameters can be calculated from the following Eq. 1 (Ross 1996):

$\eta_{\mathrm{pred}}=\eta_{\mathrm{m}}+\sum_{i=1}^{n}\left(\eta_{i}+\eta_{\mathrm{m}}\right)$

where $\eta_{\mathrm{m}}$ is the total mean of the raw data, $\sum_{i=1}^{n}\left(\eta_{i}+\eta_{\mathrm{m}}\right)$ is the all improvement (contribution) from all; $\eta_{i}$ is the mean of the raw data at the optimal level; and $n$ is the number of the beam parameters that significantly affects the performance characteristic.

Table 5 indicates the comparison of predicted values with that of actual using the critical beam parameters and the initial setting parameters (B1) of peak load, a good agreement between the actual and predicted results was obtained. For simplicity and avoiding lengthy statement the responses; namely normal stresses and strain (tensile and compressive), shear stresses and deflection at peak loads can be analyzed in a similar manner using Taguchi method. Tables 6, 7 and 8 indicate the comparison of predicted values with that of actual using the critical beam parameters and the initial setting parameters for different responses of the beams, a good agreement between the actual and predicted results were obtained.

The effect of each control factor can be determined from the value of delta and the percentage contribution, based on which Tables 5, 6, 7 and 8 show that factor $X$ (location of the applied loads) has the largest delta and the percentage contribution, and thus has the most significant influence (Rank 1) on the peak load, vertical deformation, shear stresses, and compressive normal stresses. From the same Tables, it was observed that factor $H / B$ (ratio between width and depth of the notch) is the most significant control factor affecting the compressive strain, tensile strain, and compressive normal stresses. From the same tables, it is obvious that factor NP (position of the notch) has the weakest effect on the peak load, compressive strain, tensile strain, shear stresses, and tensile normal stresses.

\section{Conclusions}

In this paper, the parameters of the artificially web damaged (opening) beam were determined from single-performance characteristics (peak load, normal stresses and strain (tensile and compressive), shear stresses and deflection at peak loads). An application of Taguchi method has been reported. Based on the numerical results achieved in the presented research study, the following conclusions can be drawn:

(1) B1 has the lowest peak load and B7 has the maximum lateral displacement from the nine notched beams. 

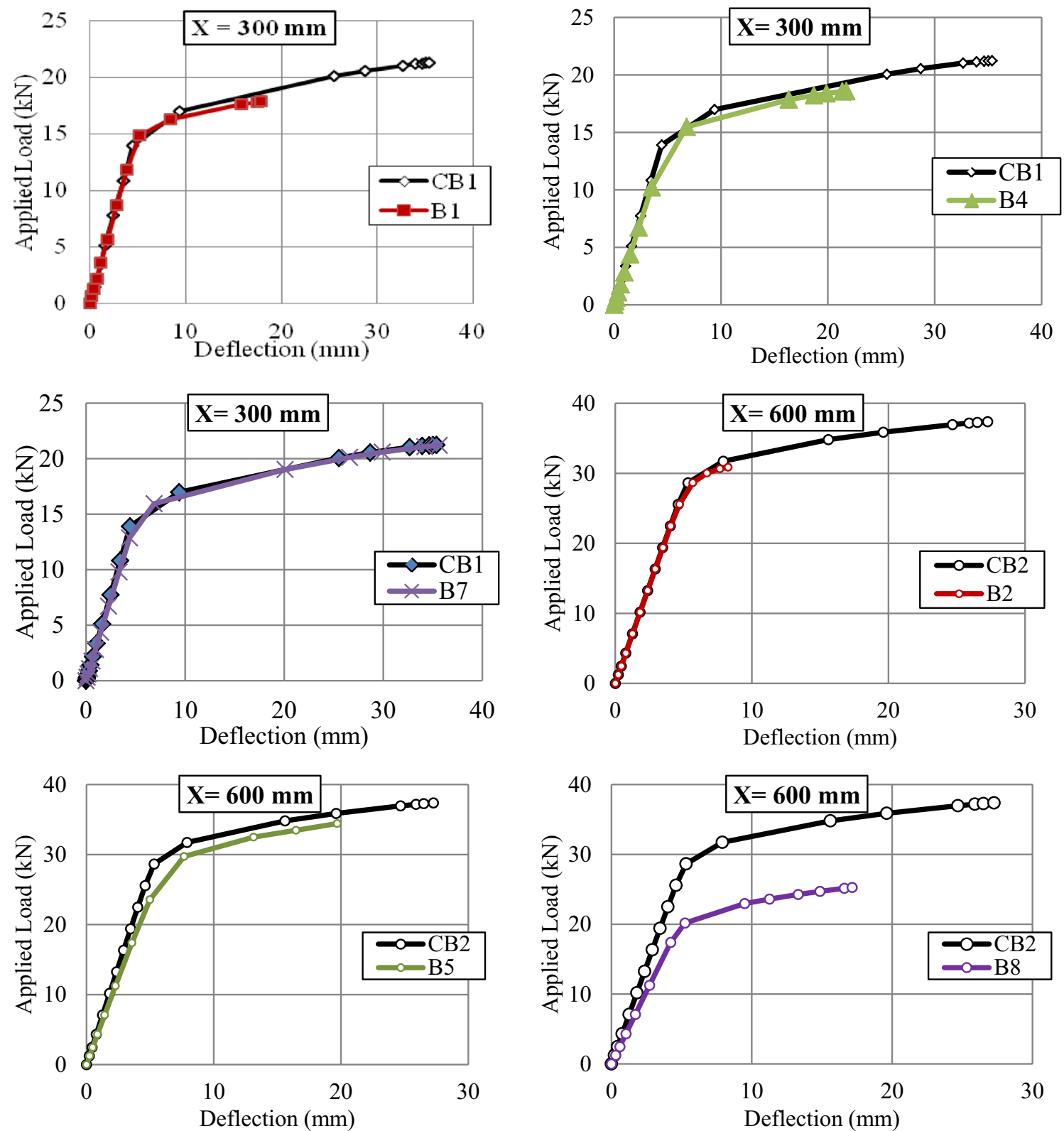

Fig. 16 Load-deflection curves at the mid-span of damaged beams and control beams

Table 5 Response table for means (raw data) and results of confirmatory experiments of peak load

\begin{tabular}{llll}
\hline Level & $H / B$ & $X$ & NP \\
\hline 1 & 33.07 & 19.16 & 40.34 \\
2 & 43.22 & 29.86 & 42.35 \\
3 & 41.42 & 68.68 & 35.02 \\
Delta & 10.15 & 49.52 & 7.34 \\
Rank & 2 & 1 & 3 \\
Contribution\% & 0.15 & 0.735 & 0.18 \\
Parameters of critical beam & 0.15 & 300 & $\mathrm{C}$ \\
Predicted value of critical beam (TAGUCHI) Eq. 1 & $8.77556 \mathrm{kN}$ & & \\
Numerical value of critical beam (ANSYS) & $14.14 \mathrm{kN}$ & & \\
Initial setting parameters (Table 4-Beam No.1) & $17.93 \mathrm{kN}$ & &
\end{tabular}


Fig. 17 The main effects plot of peak load
Main Effects Plot for Means

Data Means

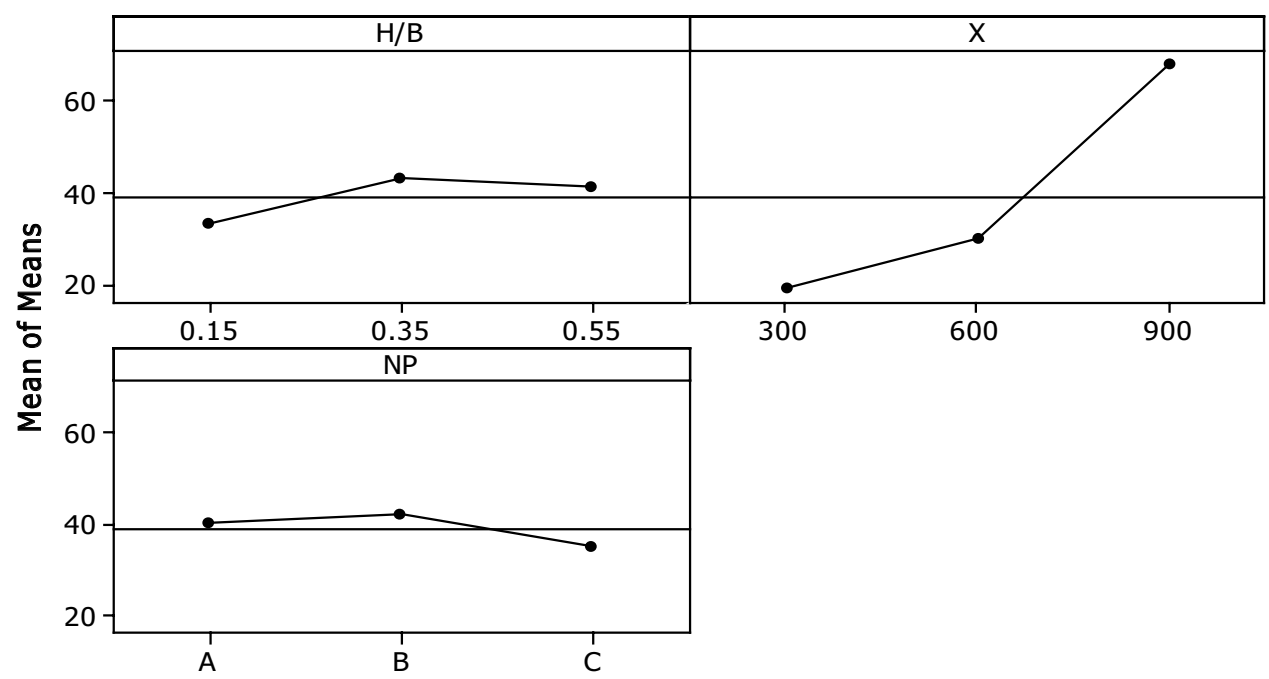

Table 6 Response table for raw date and results of confirmatory experiments of lateral displacement and shear stress

\begin{tabular}{|c|c|c|c|c|c|c|}
\hline \multirow[t]{2}{*}{ Level } & \multicolumn{3}{|c|}{ Lateral displacement } & \multicolumn{3}{|l|}{ Shear } \\
\hline & $H / B$ & $X$ & $\mathrm{NP}$ & $H / B$ & $X$ & $\mathrm{NP}$ \\
\hline 1 & 14.50 & 25.53 & 13.13 & 170.1 & 166.9 & 156.0 \\
\hline 2 & 14.05 & 15.00 & 10.32 & 191.2 & 163.4 & 186.6 \\
\hline 3 & 18.32 & 6.33 & 23.42 & 165.7 & 196.7 & 184.3 \\
\hline Delta & 4.267 & 19.20 & 13.1 & 25.5 & 33.2 & 30.6 \\
\hline Rank & 3 & 1 & 2 & 3 & 1 & 2 \\
\hline Contribution & 0.116 & 0.525 & 0.358 & 0.285 & 0.371 & 0.343 \\
\hline Parameters of desired beam & 0.55 & 300 & $\mathrm{C}$ & 0.15 & 900 & $\mathrm{~B}$ \\
\hline Predicted value of desired beam (Taguchi) Eq. 1 & $36.0198 \mathrm{~mm}$ & & & $202.089 \mathrm{Mpa}$ & & \\
\hline Numerical value of desired beam (ANSYS) & $35.75 \mathrm{~mm}$ & & & $200 \mathrm{Mpa}$ & & \\
\hline Initial setting parameters (Table 4) & $35.75 \mathrm{~mm}$ & & & 200 & & \\
\hline
\end{tabular}

Table 7 Response table for raw date and results of confirmatory experiments of normal stresses

\begin{tabular}{|c|c|c|c|c|c|c|}
\hline \multirow{3}{*}{ Level } & \multicolumn{6}{|c|}{ Normal stresses } \\
\hline & \multicolumn{3}{|l|}{ Compression } & \multicolumn{3}{|l|}{ Tension } \\
\hline & $H / B$ & $X$ & NP & $H / B$ & $X$ & NP \\
\hline 1 & 366.7 & 370.0 & 360.0 & 299.7 & 330.0 & 320.0 \\
\hline 2 & 363.3 & 366.7 & 360.0 & 360 & 339.7 & 339.7 \\
\hline 3 & 356.7 & 350.0 & 366.7 & 360 & 350.0 & 360.0 \\
\hline Delta & 10.0 & 20.0 & 6.7 & 60.3 & 20.0 & 40.0 \\
\hline Rank & 2 & 1 & 3 & 1 & 3 & 2 \\
\hline Contribution & 0.274 & 0.549 & 0.176 & 0.5 & 0.166 & 0.33 \\
\hline Parameters of desired beam & 0.15 & 300 & $\mathrm{C}$ & 0.35 & 900 & $\mathrm{C}$ \\
\hline Predicted value of desired beam (Taguchi) Eq. 1 & $378.889 \mathrm{Mpa}$ & & & $390.222 \mathrm{Mpa}$ & & \\
\hline Numerical value of desired beam (ANSYS) & $370 \mathrm{Mpa}$ & & & $370 \mathrm{Mpa}$ & & \\
\hline Initial setting parameters (Table 4 ) & $370 \mathrm{Mpa}$ & & & $370 \mathrm{Mpa}$ & & \\
\hline
\end{tabular}


Table 8 Response table for raw date and results of confirmatory experiments for strain

\begin{tabular}{|c|c|c|c|c|c|c|}
\hline \multirow[t]{3}{*}{ Level } & \multicolumn{6}{|l|}{ Strain } \\
\hline & \multicolumn{3}{|c|}{ Compression } & \multicolumn{3}{|l|}{ Tension } \\
\hline & $\overline{H / B}$ & $X$ & NP & $\overline{H / B}$ & $X$ & NP \\
\hline 1 & 0.0079 & 0.0192 & 0.0126 & 0.0066 & 0.0130 & 0.01423 \\
\hline 2 & 0.0257 & 0.0197 & 0.0167 & 0.0193 & 0.0132 & 0.00663 \\
\hline 3 & 0.0133 & 0.0079 & 0.0176 & 0.0082 & 0.0079 & 0.01327 \\
\hline Delta & 0.0178 & 0.0118 & 0.0050 & 0.0128 & 0.0053 & 0.0076 \\
\hline Rank & 1 & 2 & 3 & 1 & 3 & 2 \\
\hline Contribution & 0.513 & 0.341 & 0.145 & 0.498 & 0.205 & 0.296 \\
\hline Parameters of desired beam & 0.35 & 600 & $\mathrm{C}$ & 0.35 & 600 & A \\
\hline Predicted value of desired beam (Taguchi) Eq. 1 & 0.0317333 & & & 0.0240111 & & \\
\hline Numerical value of desired beam (ANSYS) & 0.025 & & & 0.032 & & \\
\hline Initial setting parameters (Table 4) & 0.03 & & & 0.025 & & \\
\hline
\end{tabular}

(2) B1, B2, B4, B5 and B7 reach the ultimate compressive strength of the steel. B4 and B7 reach the ultimate tensile strength of the steel (bending failure) and on the other hand, B3 reaches the steel shear strength (shear failure).

(3) The maximum stresses appear at the applied loads, at the opening position and at their surrounding area in B1, B2, B3, B4, B5 and B8 beams and on the opposite side the maximum stresses appear at the applied load position and the surrounding area in B6, B7 and B9.

(4) The opening (notch) in the beam web near the midspan and with the $H / B$ ratio $=0.15$ as in $\mathrm{B} 1$ does not have a notable effect on the beam stiffness and has effects on the beam ductility and strength compared with CB1 beam.

(5) The ductility of the steel beam subjected to two applied loads with $600 \mathrm{~mm}$ separated distance between them (CB2) largely drops due to occurrence the web notch with $H / B=0.15$ and with B notch position; B2 beam. The deflection (at the mid-span) at the ultimate load decreases by about $69.63 \%$ compared with CB2. Also the strength of this beam reduces by $17.42 \%$ than CB2.

(6) The structural performance of CB3 beam in terms of the peak load, deflection and normal stresses does not affect by the occurrence of opening in the web at position A and B as in B6 and B9, respectively.

(7) The position of the opening under the applied load and in the maximum shear zone of the beam (B3) decreases the ultimate load by about $35.24 \%$ than CB3 beam.

(8) Based on Taguchi analysis, factor $X$ (location of the applied loads) was found to be the highest contributing parameters for variation of the peak load, vertical deformation, shear stresses, and compressive normal stresses.

(9) It has been found that factor $H / B$ (ratio between width and depth of the notch) is the most significant control factor affecting the compression strain, tensile strain, and compressive normal stresses.

(10) Taguchi analysis revealed that factor NP (position of the notch) has the weakest effect on peak load, compression strain, tensile strain, shear stresses, and tensile normal stresses.

(11) Results have been confirmed on the desired beam setting parameters for single response and the errors in numerical values with respect to the predicted values are within the acceptable range of error.

(12) It can be concluded that the Taguchi method is most ideal and suitable for the parametric analysis of the artificially damaged beam when using the single-performance characteristics.

Open Access This article is distributed under the terms of the Creative Commons Attribution 4.0 International License (http://creativecomm ons.org/licenses/by/4.0/), which permits unrestricted use, distribution, and reproduction in any medium, provided you give appropriate credit to the original author(s) and the source, provide a link to the Creative Commons license, and indicate if changes were made.

\section{References}

ANSYS (2009) ANSYS help. Release 12.0, Copyright

Chung KF, Liu TCH, Ko ACH (2001) Investigation on vierendeel mechanism in steel beams with circular web openings. J Constr Steel Res 57:467-490 
Eltaly B (2016) Structural performance of notch damaged steel beams repaired with composite materials. Int Adv Struct Eng (IJAS) $8(2): 119-131$

Fisher J, Roy S (2015) Fatigue damage in steel bridges and extending their life. Adv Steel Constr 11(3):250-268

Ghazy MF (2012) Effect of using mortar interface and overlays on masonry behavior by using Taguchi method. ACI Mater J 109(5):505-516

Ghazy MF, Abd El Hameed MF (2015) Optimization of lightweight concrete process by gray-Taguchi method. ACI Mater J 112(3):365-373

Gillespie JW, Mertz DR, Edberg WM, Ammar N, Kasai K, and Hodgson IC (1996) Rehabilitation of steel bridge girders through application of composite materials. 28th International SAMPE Technical Conference, Orlando, Nov 4-7, pp 1249-1257

Kamble VS, Nagendra MV, Shinde DN (2016) Compressive strength of fly ash based Geopolymer concrete. Int J Res Appl Sci Eng Technol (IJRASET) 4(6):249-253

Kim Y, Brunell G (2011) Interaction between CFRP-repair and initial damage of wide-flange steel beams subjected to three-point bending. Compos Struct 93:1986-1996

Kim YJ, Yoon DK (2010) Identifying critical sources of bridge deterioration in cold regions through the constructed bridges in North Dakota. J Bridge Eng ASCE 15(5):542-552

Li L, Liao W, Wang J, Zhou D (2015) Behavior of continuous steelconcrete composite beams with web opening. Int J Steel Struct 15(4):989-997

Liu X, Silva PF, Nanni A (2001) Rehabilitation of steel bridge members with FRP composite materials. The International Conference on Composites in Construction, Porto, Oct 10-12, pp 613-617

May I, Roy M, Lang C, Khan R (2016) Carbon fibre-reinforced polymer for the repair of fatigue cracks in steel structures. Inst Civil Eng Struct Build 169(2):141-155
Morkhade S, Gupta L (2015) Analysis of steel I-beams with rectangular web openings: experimental and finite element investigation. Eng Struct Technol 7(1):13-23

Narmashiri K, Jumaat MZ (2011) Reinforced steel I-beams: a comparison between 2D and 3D simulation. J Simul Model Pract Theory 19:564-585

Rodrigues F, Vellasco P, de Lima L, de Andrade S (2014) Finite element modeling of steel beams with web opening. Engineering 6:886-913

Ross PJ (1996) Taguchi technique for quality engineering, 2nd edn. McGraw-Hill, New York

Shaat A (2007) Structural behavior of steel columns and steel-concrete composite girders retrofitted using CFRP. Ph. D, Thesis, Queen's University, Kingston

Shulley SB, Huang X, Karbhari VM, Gillespie JW (1994) Fundamental consideration of design and durability in composite rehabilitation schemes for steel girders with web distress. In: Proceedings of the Third Materials Engineering Conference, San Diego, Nov 13-16, pp 1187-1194

Tavakkolizadeh M, and Saadatmanesh H (2001) Repair of cracked steel girders using CFRP sheets. Proceedings of the ISEC-01 Conference, Hawaii, Jan 24-27, pp 461-466

Tavakkolizadeh M, Saadatmanesh H (2003) Repair of damaged steelconcrete composite girders using carbon fiber reinforced polymers sheets. J Compos Constr ASCE 4(7):311-322

Zhu H (2016) Mechanism of fatigue crack growth of bridge steel structures. Arch Civil Eng 62(4):153-169

Publisher's Note Springer Nature remains neutral with regard to urisdictional claims in published maps and institutional affiliations. 